\title{
Insulinoma cell calcium-sensing receptor influences insulin secretion in a case with concurrent familial hypocalciuric hypercalcemia and malignant metastatic insulinoma
}

\author{
Yasunaga Ono $^{1, *}$, Naohisa Oda ${ }^{1, *}$, Shin Ishihara ${ }^{2}$, Atsushi Shimomura ${ }^{3}$, Nobuki Hayakawa ${ }^{1}$, Atsushi Suzuki $^{1}$, \\ Akihiko Horiguchi $^{2}$, Takao Senda ${ }^{3}$, Shuichi Miyakawa ${ }^{2}$ and Mitsuyasu Itoh $^{1}$ \\ ${ }^{1}$ Division of Endocrinology and Metabolism, Department of Internal Medicine, ${ }^{2}$ Department of Surgery and ${ }^{3}$ Department of Anatomy, Fujita Health \\ University School of Medicine, Toyoake, Aichi 470-1192, Japan \\ (Correspondence should be addressed to M Itoh; Email: endolabo@fujita-hu.ac.jp) \\ *Y Ono and N Oda contributed equally to this work
}

\begin{abstract}
Context and objective: Arterial stimulation and venous sampling (ASVS) is an important technique for localizing insulinoma. The principle behind ASVS is that insulin secretion is promoted from insulinoma cells by the injection of calcium into the insulinoma-feeding artery. However, the mechanism for ASVS-induced insulin secretion remains unclear. Both insulinoma and familial hypocalciuric hypercalcemia (FHH) are rare diseases. This study reports on a case in which both of these diseases occur concurrently.

Design and patient: The patient with $\mathrm{FHH}$ also suffered from insulinoma. We reasoned that insulin secretion for ASVS is dependent on the calcium-sensing receptor (CaSR). ASVS was performed on this patient. The expression of the CaSR protein and corresponding mRNA were confirmed.

Results: No significant changes in the plasma levels of insulin and C-peptide were observed during ASVS. The patient was clinically diagnosed as having FHH. We confirmed that a mutation in the CaSR gene was present in the genomic DNA of this patient and that there were no mutations in the multiple endocrine neoplasia type 1 gene. In addition, expression of both CaSR mRNA and CaSR protein was confirmed in the insulinoma samples.

Conclusion: These results suggest that the CaSR gene is involved in ASVS-induced insulin secretion.
\end{abstract}

European Journal of Endocrinology 159 81-86

\section{Introduction}

Insulinoma is a pancreatic endocrine tumor associated with autonomous insulin secretion. The excess insulin secretion causes hypoglycemia. The local diagnosis of insulinoma is usually performed using imaging techniques such as computed tomography (CT), magnetic resonance imaging (MRI), and ultrasound. By contrast, arterial stimulation and venous sampling (ASVS) is an important technique for determining the localization of insulinomas $(1,2)$. The ASVS method was originally reported by Doppman et al. in 1991 (1), and there have been several subsequent reports of its success in localizing insulinomas $(3,4)$. The principle behind ASVS is that insulin secretion is promoted from insulinoma cells by the injection of calcium into the insulinoma-feeding artery (5). Nevertheless, the mechanism by which this is achieved remains unclear.

Kato et al. reported that the calcium-sensing receptor (CaSR) protein is expressed only on insulinoma cells and that this receptor is involved in the passage of calcium into the cell (6). However, it was subsequently reported that the CaSR protein is expressed on the surface of both insulinoma and normal $\beta$ cells (7-9). Therefore, it was important to identify if different signaling pathways involving the CaSR protein exist in insulinoma cells (10), although whether the CaSR protein represents the entry point for this pathway is still unclear.

A large number of different mutations in the CaSR gene have been identified in patients affected by the type of calcium resistance known as familial hypocalciuric hypercalcemia $(\mathrm{FHH})$. This condition is typified by dysfunction of the CaSR protein and characterized by lifelong asymptomatic hypercalcemia. FHH is inherited in an autosomal dominant fashion with almost $100 \%$ penetrance. Thus, differential diagnosis with primary hyperparathyroidism is important. It is possible to diagnose FHH by measuring fractional excretion of $\mathrm{Ca}$ (FECa), which will be $<1 \%$ in a subject with FHH (11). Neonatal severe hyperparathyroidism has a homozygous mutation in the CaSR gene (12). Both insulinoma and FHH are rare diseases, and there have been no reports of a subject with both diseases. Here, we demonstrate that a subject with FHH suffers from insulinoma and 
our results provide evidence that CaSR is related to insulin secretion in the insulinoma cell by ASVS.

\section{Case report}

A 64-year-old female was admitted to Fujita Health University Hospital because of unconsciousness, which was easily improved by administration of i.v. glucose. Plasma glucose, before the administration of i.v. glucose, was $22 \mathrm{mg} / \mathrm{dl}$. Therefore, it was determined that her unconsciousness was due to hypoglycemia.

On admission, there were no abnormal findings upon physical examination or vital signs: she was $145 \mathrm{~cm}$ tall with a body weight of $55 \mathrm{~kg}$ and her body mass index was 26.1. Her blood pressure was $136 / 74 \mathrm{mmHg}$ and she had a heart rate of $68 / \mathrm{min}$.

Clinical laboratory findings after admission were as follows: red blood cells $419 \times 10^{4} / \mu \mathrm{l}$, hemoglobin $12.6 \mathrm{~g} / \mathrm{dl}$, hematocrit $40.2 \%$, white blood cells $8500 / \mu \mathrm{l}$; platelets $30.5 \times 10^{4} / \mu \mathrm{l}$; total bilirubin $0.7 \mathrm{mg} / \mathrm{dl}$, total protein $8.6 \mathrm{~g} / \mathrm{dl}$, albumin $4.1 \mathrm{~g} / \mathrm{dl}$, aspartate aminotransferase $50 \mathrm{IU} / \mathrm{l}$, alanine aminotransferase $25 \mathrm{IU} / \mathrm{l}$, lactate dehydrogenase $208 \mathrm{IU} / \mathrm{l}$, alkaline phosphatase $292 \mathrm{IU} / \mathrm{l}$, creatine phosphokinase $87 \mathrm{IU} / \mathrm{l}$, blood urea nitrogen $29 \mathrm{mg} / \mathrm{dl}$, creatinine $0.8 \mathrm{mg} / \mathrm{dl}$, total cholesterol $264 \mathrm{mg} / \mathrm{dl}$, high-density lipoprotein cholesterol $35 \mathrm{mg} / \mathrm{dl}$, triglycerides $125 \mathrm{mg} / \mathrm{dl}$, Na $138 \mathrm{mg} / \mathrm{dl}, \mathrm{K} 5.1 \mathrm{mg} / \mathrm{dl}, \mathrm{Cl} 105 \mathrm{mg} / \mathrm{dl}$, Ca $10.6 \mathrm{mg} / \mathrm{dl}$, P $3.5 \mathrm{mg} / \mathrm{dl}$, ionic Ca $2.90 \mathrm{mg} / \mathrm{dl}$, $\mathrm{Mg} 2.3 \mathrm{mg} / \mathrm{dl}$, intact parathyroid hormone (PTH) $84.6 \mathrm{pg} / \mathrm{ml}$ (normal range 11-66 pg/ml), urinary Ca $8 \mathrm{mg} /$ day, FECa $0.384 \%$, intact PTH-related protein not detected, fasting plasma glucose $45 \mathrm{mg} / \mathrm{dl}$, insulin $16.7 \mu \mathrm{U} / \mathrm{ml}$, C-peptide $6.5 \mathrm{ng} / \mathrm{ml}$, and negative antiinsulin antibody.

Fajans' ratio and Turner's ratio, which are indices of endogenous hyperinsulinemia in insulinoma, were 0.37 and 111 respectively (i.e., positive results determined by both indices).

CT scan of the abdomen disclosed a $15 \mathrm{~mm} \times 35 \mathrm{~mm}$ tumor in the body of the pancreas and multiple metastases in the liver (Fig. 1).

The ASVS test was performed according to the method of Doppman et al. (1) preoperatively. Briefly, a sampling catheter was placed transfemorally in the right hepatic vein. After standard angiography, the following arteries were catheterized; gastroduodenal artery (GDA), splenic artery (SA), superior mesenteric artery (SMA), and hepatic artery (HA). Each artery was stimulated with calcium gluconate $\left(0.025 \mathrm{mEq} \mathrm{Ca}{ }^{2+} / \mathrm{kg}\right)$. Blood samples from the right hepatic vein were taken before and at 30 , 60, 90, and $120 \mathrm{~s}$ post-injection to measure insulin, C-peptide, and plasma glucose levels. There was no hypoglycemia during the operation.

Changes in the levels of insulin and C-peptide during ASVS are shown in Fig. 2. The serum insulin levels changed from 80.3 to 133.3 (1.66-fold) at the proximal GDA, 96.7 to 123.4 (1.27-fold) at the distal GDA, 101.3 to 132.7 (1.30-fold) at the distal SA, 86.5 to 117.6 (1.40-fold) at the proximal SA, 79.7 to 123.1 (1.54fold) at the SMA, and 76.4 to 124.8 (1.63-fold) at the HA respectively.

It is reported that a greater than two-fold step-up in insulin level within $120 \mathrm{~s}$ after injection of intra-arterial calcium is clinically required to indicate the presence of an insulinoma $(1,3,13,14)$. Therefore, there were no significant peaks of insulin or C-peptide during the ASVS.

\section{Operation methods and pathology for surgical specimens}

The following operations were performed: resection of the pancreatic body and tail and seven partial resections of the liver. Malignant insulinoma and liver metastasis: (a)

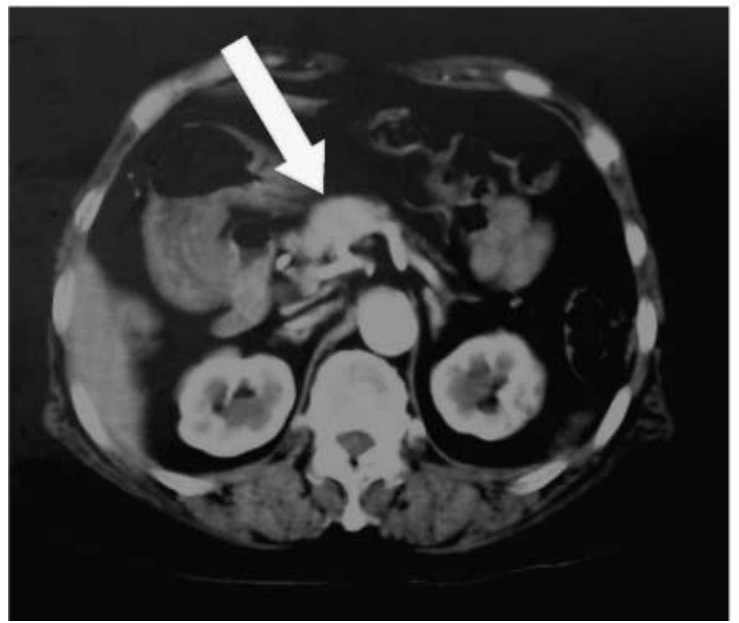

(b)

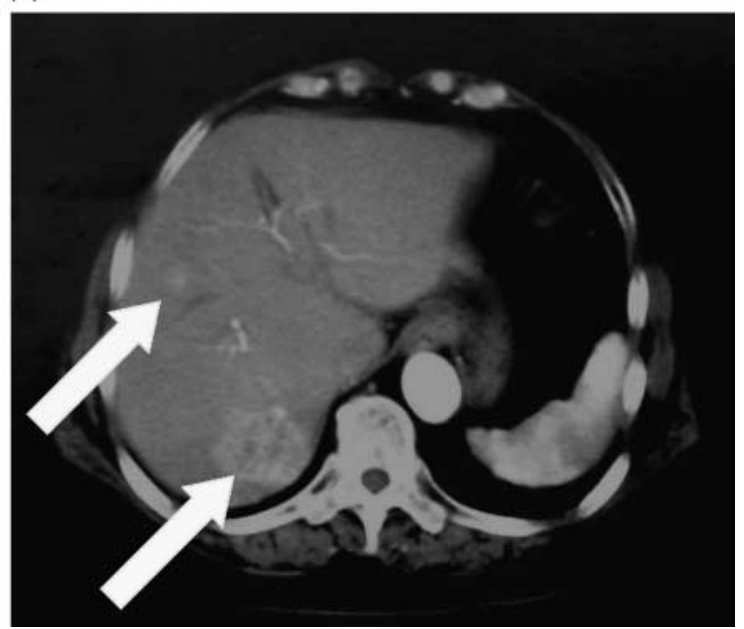

Figure 1 Dynamic CT of pancreas and liver. (a) An approximately $15 \times 35 \mathrm{~mm}$ sized early phase enhancing mass is observed at the pancreatic body. The mass is indicated by arrow. (b) Also early phase enhancing mass is observed at the liver. The mass is indicated by arrow. 

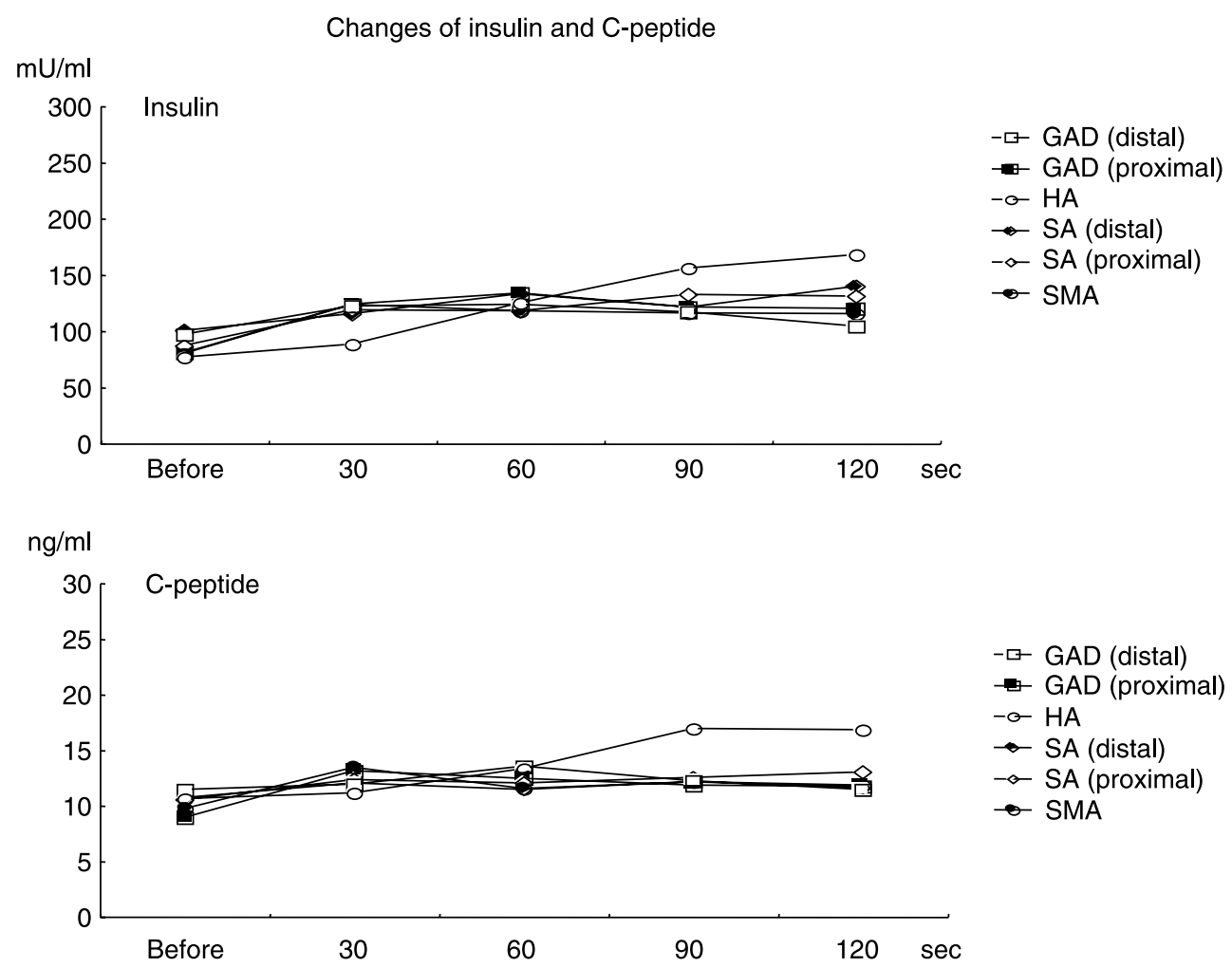

Figure 2 ASVS results. The levels of serum insulin and C-peptide were measured 0, 30,60, 90, and $120 \mathrm{~s}$ after the i.v. injection of calcium. No significant changes in the plasma level of insulin and C-peptide were observed.

the surgically resected tissue was positively stained with anti-insulin and chromogranin antibodies.

\section{Study methods}

This study was approved by the ethics committee of Fujita Health University School of Medicine. Informed consent was obtained from the patient for the use of samples for research purposes.

\section{Molecular genetics study}

The subject was screened for mutations in the exons, flanking introns of the genes encoding CaSR for $\mathrm{FHH}$ and menin for multiple endocrine neoplasia type 1 (MEN1), by direct sequencing of PCR products. All the primers used were either as published previously (12) or, in the case of MEN1, as available on the NIDDK home page (http://www.niddk.nih.gov).

\section{RNA isolation and the detection of RNA for CaSR gene by real-time PCR}

Total RNA was isolated from the tissues using RNeasy Protect mini kit (Qiagen). ThermoScript RT-PCR system (Invitrogen) was used for the synthesis of cDNA. The CaSR TaqMan probe was purchased from Applied Biosystems (Foster City, CA, USA). Real-time PCR was done using the ABI PRISM 7700 system (Applied Biosystems). The internal control used was a TaqMan probe for actin (ATCB). The expression level of the CaSR gene is shown by the ratio CaSR/ATCB. The control RNAs for both pancreatic and kidney tissues were purchased from BioChain Institute Inc. (Hayward, CA, USA).

\section{RT-PCR for the detection of CaSR mutations in RNA from pancreatic and liver samples}

The primer set was designed to amplify the region between exon 3 (5'-ttcccaacttgacgctgggatac-3') and exon 4 $\left(5^{\prime}\right.$-gctgttgctaaacctgtcgc- $\left.3^{\prime}\right)$ of CaSR. The fragment of CaSR cDNA from total RNAs from the samples was synthesized by AccessQuick RT-PCR system (Promega Co). Direct sequencing was done using the ABI PRISM310 Genetic Analyzer (Applied Biosystems).

\section{Western blot analysis}

The biopsy (operative) tissue samples from the pancreatic tumor and the liver metastases were stored at $-80^{\circ} \mathrm{C}$ until analyzed. Both the samples and the molecular weight standards were electrophoresed through $7.5 \%$ SDS polyacrylamide gels (c-PAGEL, ATTO, Tokyo, Japan) and transferred to nitrocellulose membranes (Hybond-P, Amersham Biosciences). The primary antibody used was 
rabbit anti-CaSR polyclonal antibody (Chemicon, Temecula, CA, USA), and the secondary antibody was peroxidase-labeled anti-rabbit antibody. The fluorescence was confirmed using the ECL advance Western Blotting Detection Kit (Amersham Biosciences) on the LAS1000 (Fujifilm, Tokyo, Japan).

\section{Immunohistochemistry}

Tissue derived from the pancreatic tumor and liver metastases were immersed in $10 \%$ formalin in PBS immediately after excision, fixed overnight, embedded in paraffin, and then sections of $5 \mu \mathrm{m}$ thickness were prepared. Section of parathyroid purchased from BioChain Institute Inc. was used as a positive control. Immunohistochemistry was carried out using the Envisionsystem-horseradish peroxidase (HRP) labeled polymer kit (DakoCytomation Inc., Carpinteria, CA, USA) according to the following protocol.

The sections were deparaffinized in xylene and then the tissue was rehydrated through descending strengths of ethanol, down to water. Antigen retrieval was performed in the Terget retrieval solution (DakoCytomation Inc.) for $5 \mathrm{~min}$ at $95^{\circ} \mathrm{C}$. To quench the endogenous peroxidase activity, sections were incubated in a solution of $0.03 \%$ hydrogen peroxide for $5 \mathrm{~min}$ and then incubated with rabbit anti-CaSR polyclonal antibody (Affinity BioReagents, Golden, CO, USA) diluted 1:100 with Tris-based buffer, containing $50 \mathrm{mM}$ Tris (pH 7.6) and $150 \mathrm{mM} \mathrm{NaCl}$, for $30 \mathrm{~min}$ at room temperature. As a negative control, anti-CaSR antibody was replaced by preimmune rabbit immunoglobulin ( $\operatorname{IgG})$. Binding of anti-CaSR antibody was detected with HRP-labeled polymer conjugated to antirabbit IgG (DakoCytomation Inc). Immunostaining was developed by immersion in $0.05 \% 3.3^{\prime}$-diaminobenzidine chromogen solution and then counterstained with Mayer's hematoxylin.

\section{Results}

\section{Molecular genetic study}

No mutation was detected in the menin gene for MEN1. Sequence analysis of the CaSR gene in genomic DNA showed a heterozygous G- to C-point mutation at position 961 , resulting in an amino acid substitution of proline for alanine at codon 321 (Fig. 3a and b). The same mutation was present in the subject's daughter, whose clinical data was as follows: Ca $10.9 \mathrm{mg} / \mathrm{dl}$, P $3.3 \mathrm{mg} / \mathrm{dl}$, ionic Ca $3.12 \mathrm{mg} / \mathrm{dl}$, intact PTH $58 \mathrm{pg} / \mathrm{dl}$, and FECa $0.672 \%$ respectively.

The same mutation was present in both the patient and her daughter, and both were clinically diagnosed as having FHH. Therefore, this mutation may be a cause of the FHH in both the patient and her daughter.

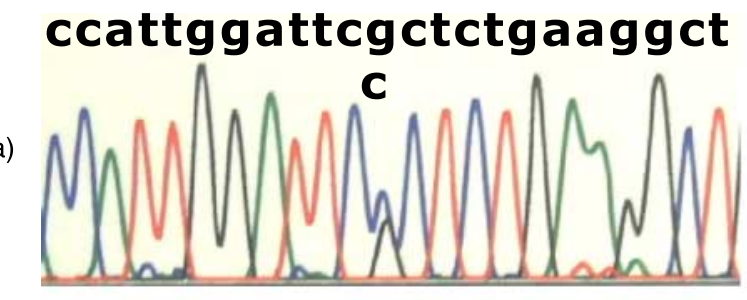

(b)

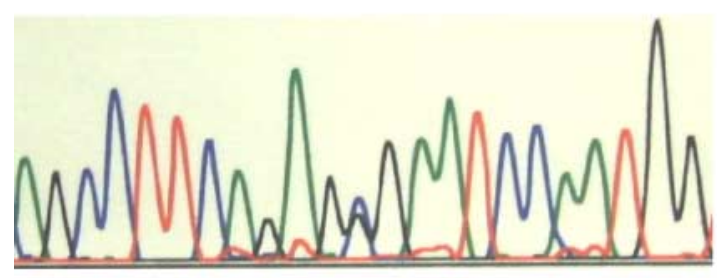

\section{cattcccag|gtcacttatgcc Exon 3}

(c)

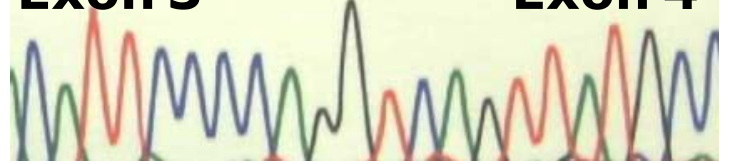

Figure 3 Mutation analysis for CaSR. (a, forward; b, reverse) Sequence analysis of CaSR exon 4 in genomic DNA extracted from the patient's peripheral blood leukocytes. A heterozygous G- to C-point mutation was identified at position 961, resulting in an amino acid substitution of proline for alanine at codon 321. (c) Sequence analysis of CaSR cDNA from RNAs of insulinoma tissues (pancreatic tumor and liver metastases). No intron was present between exon 3 and exon 4 . The same mutation was expressed in RNAs of the insulinoma tissues (data not shown).

\section{Real-time PCR for expressing CaSR mRNA}

The CaSR/ACTB ratio from the insulinomas of the pancreas and liver metastases were 2.08 and 2.65 respectively; those of normal kidney and pancreas were 2.20 and 1.00 respectively.

\section{RT-PCR for detecting CaSR mutation in the mRNA of tumors}

To confirm the expression of mutant CaSR mRNAs, tissue from both the pancreatic tumor and the liver metastases was examined by RT-PCR. The 899 bp PCR product from exon 3 to exon 4 for CaSR was synthesized. The amplified product did not contain intron 3 (Fig. 3c) and the same mutation was present in both tissue samples.

\section{Western blot analysis for the detection of CaSR protein}

Western blot studies confirmed the expression of a $120 \mathrm{kDa}$ protein that cross-reacted with the anti-CaSR antibody in the tissue samples from both the pancreatic tumor and liver metastases. However, expression levels of this protein were lower in the pancreas sample than in the liver metastases samples (Fig. 4). 


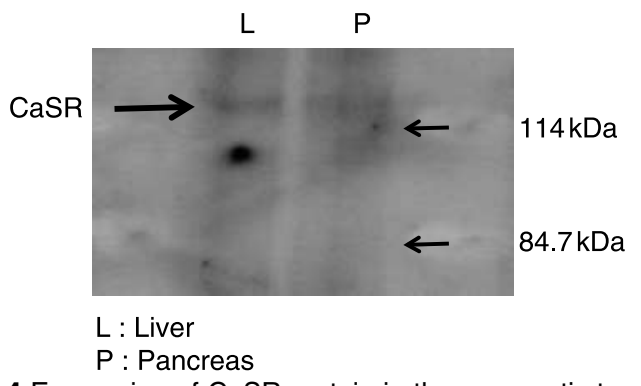

Figure 4 Expression of CaSR protein in the pancreatic tumor and the liver metastasis samples. The samples were subjected to $7.5 \%$ SDS-PAGE and the fluorescence was confirmed. The positions of 114 and $87 \mathrm{kDa}$ markers are indicated by arrows. The band of about $120 \mathrm{kDa}$ corresponding to the CaSR protein was observed in both the pancreatic tumor and the liver metastasis samples.

\section{Immunohistochemistry}

In addition, we also confirmed the expression of CaSR protein using immunohistochemical analysis. The pancreatic tumor was immunoreactive with anti-CaSR antibody (Fig. 5(a)). In addition, the liver metastases were also stained (Fig. 5(c)). Negative control samples treated with preimmune rabbit IgG instead of anti-CaSR antibody were unstained (Fig. 5(b) and (d)). As a positive control, parathyroid tissue was stained using the anti-CaSR antibody (Fig. 5(e)). As can be seen in the figures, the staining of the liver metastases was intense compared with that of the pancreatic tumor.

\section{Discussion}

The patient we report here was suffering from both FHH and insulinoma concurrently.

The daughter of the patient also suffered from the same form of hypercalcaemia. Therefore, we reasoned that the hypercalcaemia might explain the FHH. There was no pituitary adenoma in the MRI. No mutation in the menin gene was found in the genetic test and there was no family history of this disease. Therefore, we excluded MEN1.

If insulinoma cells showed a poor response to calcium injection, this may indicate that the mechanism for insulin secretion by ASVS was linked with the CaSR protein. This case is important because the insulinoma with the mutant CaSR gene showed a poor response following ASVS, thereby indicating that signaling via the CaSR gene is probably associated with ASVSinduced insulin secretion. However, calcium infusion did not stimulate insulin secretion from an insulinoma in every patient, even in the absence of FHH. Therefore, the negative ASVS test observed in the present study does not necessarily indicate that the mutation of CaSR is responsible for the observed phenomenon.

Despite the fact that insulin secretion was not completely suppressed, the mechanism indicates that the subject was heterozygous for a mutation in the CaSR gene. The fact that the subject had hypercalcemia as well as MEN1 before the ASVS test did not seem to have an effect on the secretion of insulin (14).
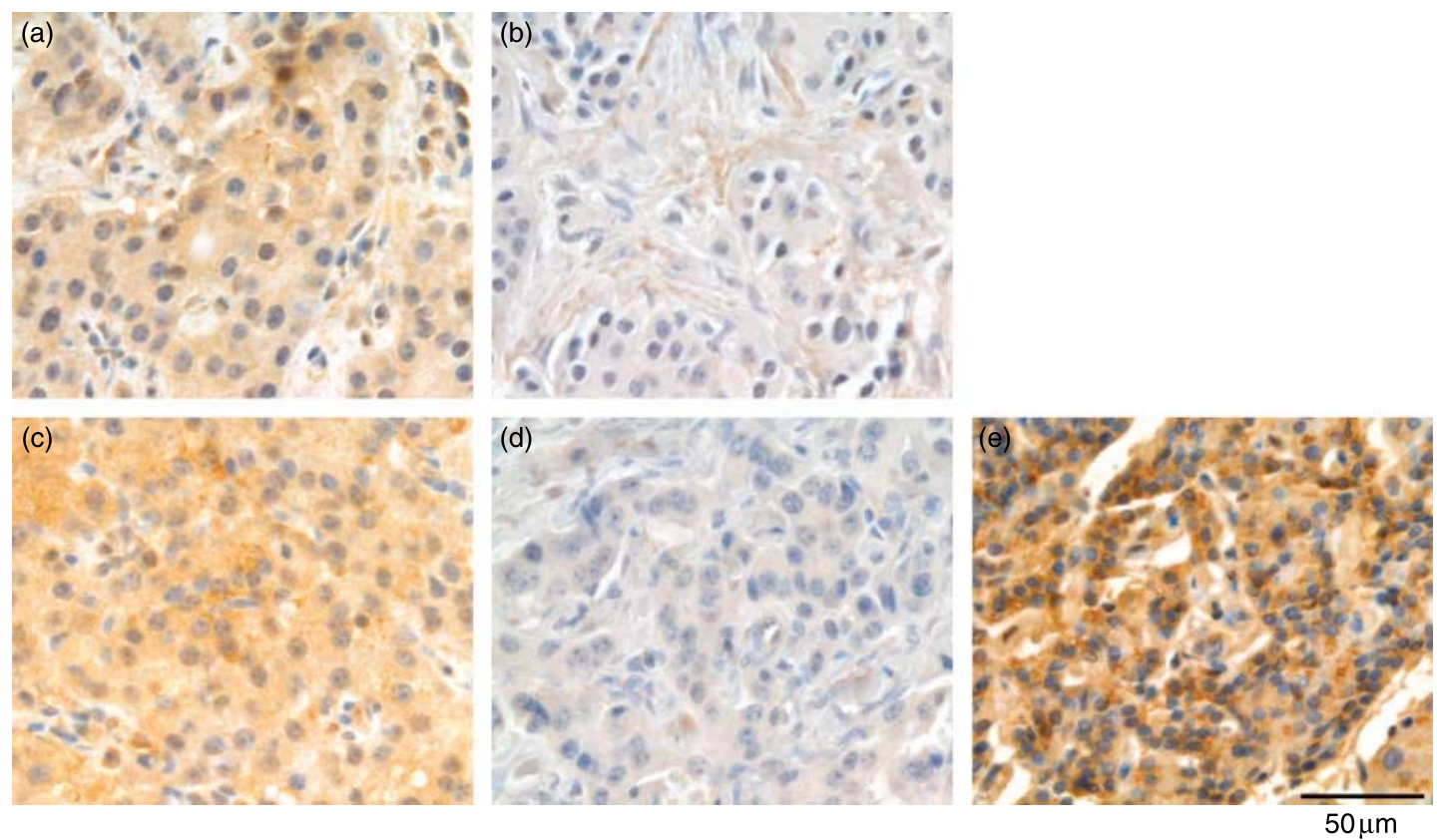

Figure 5 Immunohistochemistry. (a) Pancreatic tumor (rabbit anti-CaSR antibody). (b) Pancreatic tumor (preimmune rabbit lgG, negative control). (c) Liver metastatic tumor (rabbit anti-CaSR antibody). (d) Liver metastatic tumor (preimmune rabbit IgG, negative control). (e) Normal parathyroid tissue (rabbit anti-CaSR antibody, positive control). Both insulinoma tissues of pancreas and liver were stained by anti-CaSR antibody. 
The function of CaSR is best examined in the parathyroid gland. When extracellular calcium $\left(\left[\mathrm{Ca}^{2+}\right] \mathrm{o}\right)$ combines with CaSR, the intracellular calcium $\left(\left[\mathrm{Ca}^{2+}\right] \mathrm{i}\right)$ concentration rises due to mobilization from the calcium stores in the endoplasmic reticulum through the Gq/11 protein-phosphatidylinositol 3-kinase pathway and the activation of protein kinase $\mathrm{C}(15)$. The activity of CaSR suppresses PTH secretion. In the event of ASVS-induced insulin secretion, the levels of serum insulin reach a peak within $40 \mathrm{~s}$ of the start of the calcium infusion (2). Kato et al. reported that a high $\left[\mathrm{Ca}^{2+}\right] \mathrm{o}$ concentration immediately evoked an increase in the release of insulin from human insulinoma cells in vitro, and that the level of $\left[\mathrm{Ca}^{2+}\right] \mathrm{i}$ in insulinoma cells rose immediately after the concentration of $\left[\mathrm{Ca}^{2+}\right]$ o was increased (6). However, it is thought that normal islet and insulinoma cells respond differently to changes in the concentration of $\left[\mathrm{Ca}^{2+}\right]$; human insulinoma cells respond to lower concentrations of $\left[\mathrm{Ca}^{2+}\right]$ o than normal $\beta$-cell (10). These elevated levels of $\left[\mathrm{Ca}^{2+}\right] \mathrm{i}$ are induced by the mobilization of phosphatidylinositol 3-kinase-gated stored $\mathrm{Ca}^{2+}(10)$. However, it is not known whether the gateway for this response is the CaSR protein on the cell surface.

From the findings reported in this study, it appears that intact CaSR is essential for insulin secretion in response to calcium infusion. The mechanism of secretion of insulin may be similar to gastrin release from gastrinoma cells in response to the i.v. calcium injection $(16,17)$.

\section{References}

1 Doppman JL, Miller DL, Chang R, Shawker TH, Gorden P \& Norton JA. Insulinomas: localization with selective intraarterial injection of calcium. Radiology 1991178 237-241.

2 Doi R, Komoto I, Nakamura Y, Kawamura J, Fujimoto K, Wada M, Saga T \& Imamura M. Pancreatic endocrine tumor in Japan. Pancreas 200428 247-252.

3 Kirchhoff TD, Merkesdal S, Frericks B, Brabant G, Scheumann G, Galanski M \& Chavan A. Intraarterial calcium stimulation (ASVS) for pancreatic insulinoma: comparison of preoperative localization procedures. Radiologe $2003 \mathbf{4 3} 301-305$.

4 Brandle M, Pfammatter T, Spinas GA, Lehmann R \& Schmid C. Assessment of selective arterial calcium stimulation and hepatic venous sampling to localize insulin-secreting tumours. Clinical Endocrinology 200155 357-362.
5 Gaeke RF, Kaplan EL, Rubenstein A, Starr J \& Burke G. Insulin and proinsulin release during calcium infusion in a patient with isletcell tumor. Metabolism 197524 1029-1034.

6 Kato M, Doi R, Imamura M, Furutani M, Hosotani R \& Shimada Y. Calcium-evoked insulin release from insulinoma cells is mediated via calcium-sensing receptor. Surgery $1997 \mathbf{1 2 2} 1203-1211$.

7 Won JG, Tseng HS, Yang AH, Tang KT, Jap TS, Kwok CF, Lee CH \& Lin HD. Intra-arterial calcium stimulation test for detection of insulinomas: detection rate, responses of pancreatic peptides, and its relationship to differentiation of tumor cells. Metabolism 2003 52 1320-1329.

8 Rasschaert J \& Malaisse WJ. The G-protein-coupled, extracellular $\mathrm{Ca}\left({ }^{2+}\right)$-sensing receptor: expression in pancreatic islet B-cells and possible role in the regulation of insulin release. Molecular Genetics and Metabolism 199968 328-331.

9 Rasschaert J \& Malaisse WJ. Expression of the calcium-sensing receptor in pancreatic islet B-cells. Biochemical and Biophysical Research Communications 1999264 615-618.

10 Komoto I, Kato M, Itami A, Shimada Y, Doi R, Hosotani R \& Imamura M. Expression and function of the calcium-sensing receptor in pancreatic islets and insulinoma cells. Pancreas 2003 26 178-184.

11 Marx SJ. The hypocalciuric or benign variant of familial hypercalcemia: clinical and biochemical features in fifteen kindreds. Medicine 198160 397-412.

12 Pollak MR, Brown EM, Chou Y-HW, Hebert SC, Marx SJ, Steinmann B, Levi T, Seidman CE \& Seidman JG. Mutations in the human $\mathrm{Ca}\left({ }^{2+}\right)$-sensing receptor gene cause familial hypocalciuric hypercalcemia and neonatal severe hyperparathyroidism. Cell 199375 1297-1303.

13 Wiesli P, Brandle M, Pfammatter T, Zapf J, Spinas GA \& Schmid C. Insulin determination by specific and unspecific immunoassays in patients with insulinoma evaluated by the arterial stimulation and venous sampling test. European Journal of Endocrinology 2004151 123-126.

14 Lo CY, Chan FL, Tam SC, Cheng PW, Fan ST \& Lam KS. Value of intra-arterial calcium stimulated venous sampling fof regionalization of pancreatic insulinomas. Surgery $2000 \mathbf{1 2 8} 903-909$.

15 Brown EM \& MacLeod RJ. Extracellular calcium sensing and extracellular calcium signaling. Physiological Reviews $2001 \mathbf{8 1}$ 239-297.

16 Goebel SU, Peghini PL, Goldsmith PK, Spiegel AM, Gibril F, Raffeld M, Jensen RT \& Serrano J. Expression of the calciumsensing receptor in gastrinomas. Journal of Clinical Endocrinology and Metabolism 2000 85 4131-4137.

17 Itami A, Kato M, Komoto I, Doi R, Hosotani R, Shimada Y \& Imamura M. Human gastrinoma cells express calcium-sensing receptor. Life Sciences 200170 119-129.

Received 26 March 2008

Accepted 16 April 2008 